\title{
Scope of International Accreditation in Improvement of "Quality of Care and Patient Safety" Overview
}

\author{
Bobish Kandy ${ }^{1}$, Dr. Junior Sundaresh ${ }^{2}$ \\ ${ }^{1}$ Student, MBA, Hospital Management, Annamalai University, Chidambaram, Chennai, Tamilnadu, India \\ bob150574[at]gmail.com
}

${ }^{2}$ Project Guide, Annamalai University, Associate Professor of Surgery, Rajah Muthiah Medical College, Annamalai University, Chithambaram, Chennai, Tamilnadu, India

\begin{abstract}
This project study identifies the "Scope of Accreditation Process" and to understand the needs of maintaining\& improving the "Quality of Care and Patient Safety" by ensuring their certifications and accreditations. This study also assesses how the accreditation ensures the best practices which are internationally acceptable, typically meaning that they are competent to test and certify third parties, behave ethically and employ suitable Quality of Care and Patient Safety.
\end{abstract}

Keywords: Quality Accreditations, Quality Standards, Quality of Care, Patient Safety

\section{Introduction}

India is one of the leading players in healthcare domain in the present world. A huge volume of well-trained physicians and supporting staff, state-of-the-art medical technology and highly affordable cost structure make India a preferred healthcare destination.

Accreditations and improvement of "Quality of Care and Patient Safety" in India are geared towards better Quality Management and dominance in the international healthcare arena. This study was led by Project Lead Dr. Junior Sundaresh, Annamalai University, Tamilnadu, India.

\section{Purpose of this Survey}

The survey aims to identify the scope of the accreditations in improvement of "Quality of Care and Patient Safety" in India. It also aims to determine how the accreditation process can help in the development of patient focused centers of patient safety and sustained application of relevant International standards.

The purpose of quality accreditation is to maintain standards and their elements of performance as well as Key Performance Indicators ensure significant time is spent in consultation and education and thus improving patient safety.

\section{International Accreditation Survey Overview}

International Accreditation surveys provide an assessment of an organization's compliance with standards and their elements of performance.

International Accreditations evaluate an Organization's compliance based on:

- Patient and staff interviews via tracer methodology about Actual practice.

- Performance improvement data/trends
- Verbal information provided at International Accreditation Agency during survey.

- On-site observation by International Accreditation Agency surveyors.

\subsection{Characteristics of Accreditation Survey}

An accreditation survey has the following characteristics:

- Voluntary (although it may be mandatory such as NABH); the institution wishing to be accredited pays a fee to the accrediting organization.

- Principal goal is institutional development or improvement of its performance; preferably, with afocus on patients (including research subjects).

- Authorized body (usually a non-government organization) that performs the accreditation process; authority stems from the legitimacy of the accrediting organization's founders or sponsors and/or itscharter, Example: JCIA, NABHetc.

- Based on written/published standards (preferably available at no or nominal cost); transparent standard-settingprocess, including the opportunity for public comment.

\subsection{Accreditation Survey Process}

The process of accreditation generally involves:

- Application by the institution (applicant) that wants to be accredited.

- Performance and submission by the applicant of a "selfassessment."

- Desk review of the applicant's submission, often including the self-assessment.

- Site visit to the applicant (often called a "survey") by certified assessors (often called "surveyors") inwhich assessors may inspect premises, documents, etc, interview staff, observe processes, review (samples of) records (and may conduct "compliance tests"); generally accrediting organizations trainand certify their own assessors, who are 


\section{International Journal of Science and Research (IJSR) \\ ISSN (Online): 2319-7064}

Index Copernicus Value (2016): 79.57 | Impact Factor (2015): 6.391

mostly volunteers (and are often peers or colleagues of peoplein the institutions being accredited).

- Exit de-briefing in which assessors may provide initial feedback to the applicant's management team,in part to test the validity of conclusions and to ensure that there are no surprises in the accreditationreport.

\subsection{Different Types of Accreditation Standards}

There are different types of Accreditation Standards for a Hospital, Tertiary and Clinic as below, to provide a safe, effective, and well-managed organization.
- Ambulatory Care Standards
- Care Continuum Standards
o Clinical Care Program Certification Standards
- Clinical Laboratory Standards
- Hospital Standards
- Medical Transport Organization Standards
o Primary Care Center Standards

\section{Outputs of Accreditation and Quality Improvement}

According to the international literature, in order to improve performance, health systems could capitalize further on the nursing profession, in particular, the scope of nursing practice and the introduction of advanced nursing roles. Ultimately, the patient and the health care system would benefit from these performance gains.

\subsection{Chart Number 1}

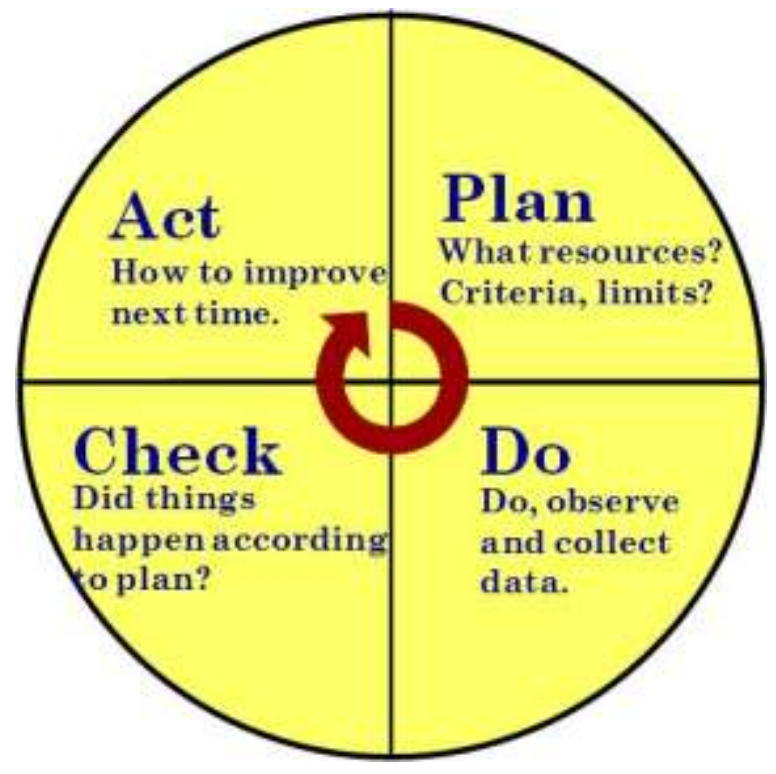

What is PDCA ?

Quality Plan-Do-Check-Act (also called "PDCA") is a cycle that was originated by Walter Shewhart and made popular by Edward Deming - two of the fathers of modern quality control. This concept is a cycle for implementing change which, when followed and repeated, would lead to repeated improvements in the process it was applied to. This cycle lead to improve the system in optimal use of available resources. -(Refer Para 4.1.Chart Number $1 \&$ chart number 2 to understand the PDCA cycle).
To understand the basic quality management principles, refer the Para 4.3 Chart Number 3

\subsection{Chart Number 2.}

PDCA CYCLE (Deming circle/cycle/wheel, Shewhart cycle etc.)

- Plan: establish the objectives of the system and its processes, and the resources needed to deliver results in accordance with customers' requirements and the organization's policies, and identify and address risks and opportunities;

- Do: implement what was planned;

- Check: monitor and (where applicable) measure processes and the resulting products and services against policies, objectives, requirements and planned activities, and report the results;

- Act: take actions to improve performance, as necessary

\subsection{Benefits of Accreditation}

The literature provides data on the systemic effectiveness and efficiency gains generated by the optimal use of staff which benefits patients in many ways:

4.1. Improved quality of care

4.2. Lives saved and prolonged lives

4.3. Improved patient health and quality of life

4.4. Fewer adverse events

4.5. Complications and admissions avoided

4.6. Better continuum of care, reducing the use of more costly care

4.7. Better management of chronic diseases

4.8. Increased patient well-being

4.9. Improved pain management

4.10.Adoption of healthy lifestyle behaviours at different levels of prevention

4.11.Better access to health care

4.12. More rapid diagnosis and treatment

4.13.Improved patient compliance to treatment and medication;

4.14.Improved patient follow-up;

4.15.Improved care transition to the community;

4.16. Overall reduction in health system expenditure

4.17.Improved Patient Safety

4.18.Improved Trainings

4.19.Improved Documentation to protect staff and organization from Medico-legal cases

4.20.Prevention of Hospital Acquired Infections among patients and staff

4.21.Improved Adequacy of staff

4.22. Technological Advancement etc. 


\subsection{Basic Quality Management Principles}

Chart Number 3

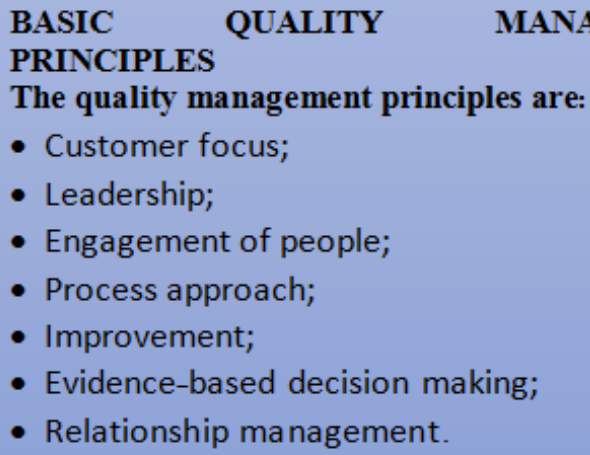

\section{Scope of Quality Accreditations in India}

According to Quora Search in India, around 4,419 hospitals are in urban areas with $\mathbf{4 , 3 2 , 5 2 6}$ beds. Medical care facilities under Ayush by management status i.e. dispensaries \& hospitals are $\mathbf{2 6 , 1 0 7} \& \mathbf{3 , 1 6 7}$ respectively as on March 2013. Also, there are $\mathbf{1 , 5 1 , 6 8 5}$ Sub centers, 24,448 Primary Health centers and $\mathbf{5 , 1 8 7}$ Community Health Centers in India as on March 2013.

\subsection{NABH Accredited Hospitals}

Out of over 50,000 recognized Hospitals and Labs in the Country, only about 850 Hospitals \&760 Labs as listed on this Platform have been approved by NABH \& NABL.

Source: https://www.quality health.in/nabh

\subsection{JCI accredited hospitals}

In India, there are $21 \mathrm{JCI}$ accredited hospitals in its major cities.

\subsubsection{Aditya Birla Health Services Ltd., Pune}

\subsubsection{Ahalia Foundation Eye Hospital, Palakkad, Kerala}

Ahalia Foundation Eye Hospital, a unit of Ahalia International Foundation started in 2005 is the realization of a long cherished dream of a group of NRIs. Ahalia stands tall on a rock solid reputation of reliability, affordability, quality and innovation.

\subsubsection{Apollo Gleneagles Hospitals, Kolkata}

Apollo Gleneagles Hospital, Kolkata is a joint enterprise between Apollo Group and the Parkway Group of Singapore. This 325 bed multi-speciality hospital has a well equipped wide range of specialized clinic.

\subsubsection{Apollo Hospital, Chennai}

It is one of the most respected hospitals in the world, and is also amongst the most preferred destinations for both patients from India, as well as for medical tourists. The hospital specializes in radical medical procedures. It is led by internationally trained doctors and nurses.

\subsubsection{Apollo Hospital, Hyderabad}

Apollo Hospitals, Hyderabad has its name as one of the best in the world, in terms of technical capability, deliverables and outcomes. Having over 350 beds, this multi-specialty hospital offers the best care in the safest manner to every patient.

\subsubsection{Apollo Hospitals, Bangalore}

Apollo Hospitals, Bangalore is one among the top hospitals in the world to be JCI certified. The medical faculty comprises of some of the best in the medical fraternity. The hospital is equipped with some of the most advanced facilities in the world and some of the most renowned names in several medical specialties and super specialties.

\subsubsection{Artemis Health Institute (a unit of Artemis Medicare Services Ltd.), Gurgaon}

\subsubsection{Asian Heart Institute, Mumbai}

The AHI was set up in order to provide a holistic approach to cardiac care based on ethics, quality care and professional services at reasonable rates. They also provide various diagnostic services. They have been certified by the ISO 9001: 2000, JCI and NIAHO. To contribute to medical tourism, their services include airport pick-up and drop, providing hotel accommodations, arranging prior appointments with consultants, internet facilities, pharmacy facilities, blood bank, counseling etc.

\subsubsection{Fortis Escorts Heart Institute, New Delhi}

This 272 bedded hospital which has 5 cathlabs, a team of highly qualified and dedicated staff, world class infrastructure and various other services such as air- lift facilities, mobile CCUs, heart alert services etc is truly a pioneer in the field of cardiac care. Honored with the ISO 9001:2001 certification, the Super brand 2008 award and accredited by the JCI, NABH and NABH (Blood Bank), they provide various pre - departure, post admission and post discharge services at nominal rates.

\subsubsection{Fortis Hospital, Mohali}

Fortis Hospital Mohali, is a super specialty hospital of our country with a capacity of 300 beds and have seven operation theatres. This hospital has not only found a place amongst India's most advanced cardiac hospitals, but is now also a well-recognized multispecialty facility with many accomplishments. 


\subsubsection{Fortis Hospital, Bangalore}

Fortis Hospitals, Bangalore is centre for excellence in interventional Cardiology and Cardiac Surgeries in the country. it is the first hospital in India to have performed the Conscious Off Pump Coronary Artery Bypass Surgery and Awake

Heart

Surgery.

\subsubsection{Fortis Hospital, Mulund}

The Fortis Hospitals, Mulund was formerly called as the Wockhardt Hospital located at the Mulund area in Mumbai. It is a multi speciality hospital which is well equipped with the world-class equipment\& technology. This 222 patient bedded hospital has 9 specially designed and equipped operating rooms.

\subsubsection{Grewal Eye Institute Private Ltd, Chandigarh}

The institute caters to about 150 outpatient cases per day and performs about 1500 surgeries per year which includes minor \& major surgeries including Phacoemulsification (stitch less surgery) for Cataract, iLasik for removal of glasses, Corneal Transplant, Vitreo Retinal surgery, Squint surgery \& Glaucoma surgery.

\subsubsection{Indraprastha Apollo Hospital, New Delhi}

Indraprastha Apollo is one of the largest corporate hospitals in the world. It is the third super specialty tertiary care hospital set by the Apollo Hospitals Group, jointly with the Government of New Delhi, India's capital. It is a 695 bedded hospital, with the provision for expansion to 1000 beds in future.

\subsubsection{Medanta - The Medicity}

\subsubsection{Moolchand Hospital, New Delhi}

Moolchand is India`s premier international hospital providing world-class healthcare for patients from 190+ countries. They are India's First JCI (Joint Commission International) and Comprehensive NABH (National Accreditation Board for Hospitals and Healthcare Providers) Accredited Hospital and are recipients of various national and international awards.

\subsubsection{Narayana Hrudayalaya Pvt. Ltd., Bangalore}

Narayana Hrudayalaya headed by Dr.Devi Shetty, is a medical institute in India where people from all classes are treated at par. There are various provisions wherein the poor can be benefited of the services at a subsidized rate. The Thombosis Research Institute, a part of Narayana Hrudayalaya is operational in developing a vaccine to prevent early atherosclerosis.

\subsubsection{Narayana Multispeciality Hospital, Jaipur}

\subsubsection{Satguru Pratap Singh Apollo Hospital, Ludhiana}

The hospital is the first of its kind in this region performing super specialty procedures and has a wide range of investigative, preventive and therapeutic facilities aiming to provide complete healthcare services under one roof. It has the most qualified and talented medical professionals and other management staff. With over 350 beds, this hospital offers affordable health-care services to its patients.

\subsubsection{Shroff Eye Hospital / Shroff Eye Clinic, Mumbai}

Shroff Eye has stood for excellence in eye care since 1919. A firm commitment to quality is at the heart of all services provided at their centers at Bandra (W) and Marine Drive, Mumbai.

\subsubsection{Sri Ramachandra Medical Centre, Chennai}

Sri Ramachandra Medical Centre (SRMC) is a multispeciality hospital in Chennai. Today, SRMC is a leader in health care delivery in South India providing cutting edge state-of-art care for its patients. The medical centre is an eight storied building with more than 600 beds. The medical aid offered here is considered to be one of the best in the country.

Note: Latest list can be accessed from: http://www.jointcommissioninternational.org/about-jci/jciaccredited-organizations/?c=India

\section{Opinion Survey on Need of Quality Accreditations}

A public Opinion poll survey was conducted in India to identify the opinion of different classes of people. The Question in the survey was "How strongly do you agree with the opinion that an accreditation agency can assure quality assurance in a healthcare organization efficiently and effectively?"

The survey inclusion and exclusion criteria included factors such as Category of people - Physicians, Patients, type, other medical, psychosocial, or emotional conditions etc.

The survey was conducted among 653 members of different categories as mentioned in Table 5.1. Graphical representation of the same data is given in Table 2 .

More than 50 to $75 \%$ of the people who attended the survey either agreed or strongly agreed in response to the survey question. 
International Journal of Science and Research (IJSR)

ISSN (Online): 2319-7064

Index Copernicus Value (2016): 79.57 | Impact Factor (2015): 6.391

Table 5.1

\begin{tabular}{|c|c|c|c|c|c|c|}
\hline \multirow[b]{2}{*}{ Category People } & \multicolumn{5}{|c|}{ Opinion } & \multirow[b]{2}{*}{ Total } \\
\hline & $\begin{array}{l}\text { Strongly } \\
\text { Disagree }\end{array}$ & Disagree & Neutral & Agree & Strongly Agree & \\
\hline Physicians and Specialists & 2 & 1 & 3 & 18 & 21 & 45 \\
\hline Patients & 0 & 3 & 40 & 85 & 115 & 243 \\
\hline Nursing Staff & 0 & 0 & 10 & 86 & 176 & 272 \\
\hline Allied Healthcare workers & 0 & 0 & 0 & 10 & 20 & 30 \\
\hline Insurance Company staff & 0 & 0 & 2 & 3 & 5 & 10 \\
\hline Others & 1 & 2 & 12 & 18 & 20 & 53 \\
\hline Grand Total & 3 & 6 & 67 & 220 & 357 & 653 \\
\hline
\end{tabular}

Table 5.2

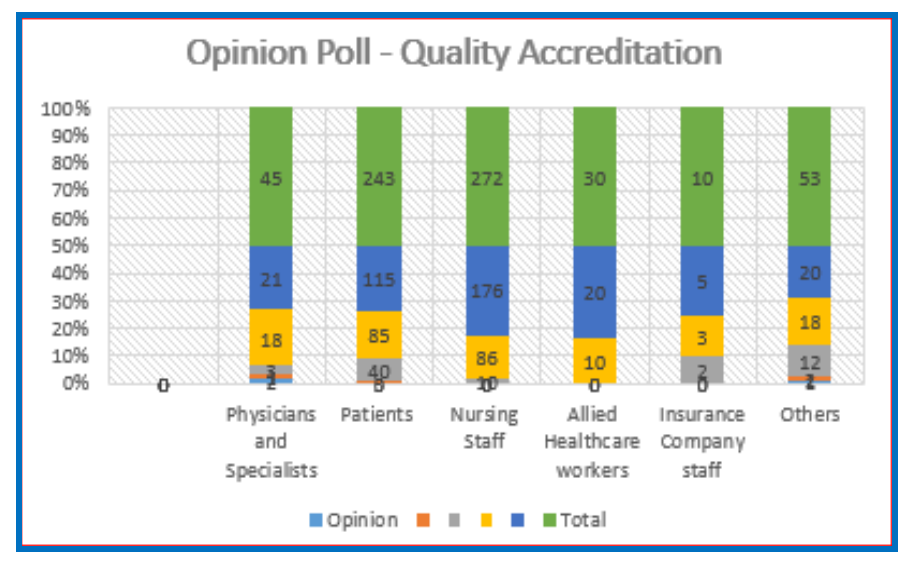

\section{Accreditation can Improve Patient Safety?}

Another objective of this project was to identify areas and potential to explore specific dimensions of care. These address the following aspects of patient experiences.

7.1. Admission processes - Waiting to be taken to a room/ward/bed. The issue is not actual waiting times but the patient's perception of how problematic it was.

7.2. Patient Communication - Focusing on patient assessments of the adequacy of information provided about the condition or treatment, and the extent to which patients believed they had opportunities to ask questions.

7.3. Patient involvement in decision-making - Focusing on patient assessments of the adequacy of their involvement in decision-making.

7.4. Patients Treated with respect- views on whether hospital staff treated them with courtesy, respect, politeness and/or consideration. These questions were asked separately for both doctors and nurses. Patient assessments of the extent to which cultural and religious needs were respected could also be included.

7.5. Privacy - Patient assessments on the extent to which their privacy was respected.

7.6. Responsiveness of staff - The survey included a patient experience question related to how long nurses took to respond to a call button. Related questions concerning availability of healthcare staff were included.
7.7. Management of pain- patient assessment of how well their pain was managed.

7.8. Medication management Information- related information adequacy was assessed.

7.9. Physical environment - Patient assessments of cleanliness of rooms and toilets/bathrooms, quietness/restfulness, and quality of food.

7.10.Patient rights and feedback - Patient assessments of how complaints were handled and whether they were informed of their rights.

7.11.Discharge - Information provided at discharge on to how to manage the patient's condition.

The questionnaire contained 50 items. All experience-related statements used a five point Likert scale ranging from 'always' (5) to 'never' (1). A 'does not apply' column was included for all relevant sections. It is noted that 4-point Likert scales tend to distort the answers, as there is no neutral mid-point. This can lead to survey bias as respondents are forced to select a side. Therefore, answers tend to be skewed to one side, which is avoided if a 5-point Likert scale is used. A 5-point scale gives respondents more scope to contemplate on which side to respond. Questions related to patient rights and feedback were 'yes', 'no', and 'does not apply'.

The feedback received was supporting the necessity of Quality of Care and Patient Safety in all above aspects. 


\section{International Journal of Science and Research (IJSR) \\ ISSN (Online): 2319-7064}

Index Copernicus Value (2016): 79.57 | Impact Factor (2015): 6.391

\section{Conclusion}

The growing worldwide demand and concern for quality care and for effective mechanisms leads to the demand of accreditations, Certifications and technology assessment to improve the Quality of Care and Patient Safety.

\section{References}

[1] Wilson RM, Michel P, Olsen S, Gibberd RW, Vincent C, El-Assady R, et al. WHO Patient Safety EMRO/AFRO Working Group. Patient safety in developing countries: Retrospective estimation of scale and nature of harm to patients in hospital. BMJ. 2012;344:e832. [PubMed]

[2] Amexo M, Tolhurst R, Barnish G, Bates I. Malaria misdiagnosis: Effects on the poor and vulnerable. Lancet. 2004;364:1896-8. [PubMed]

[3] General Information on Counterfeit Medicines [Internet] World Health Organization. [Last cited on 2014 Aug 8]. Available from: http://www.who.int/medicines/services/counterfeit/ov erview/en/

[4] Kermode M. Unsafe injections in low-income country health settings: Need for injection safety promotion to prevent the spread of blood-borne viruses. Health Promot Int. 2004;19:95-103. [PubMed]

[5] World Health Organization. Quality of Care: Patient Safety. World Alliance for Patient Safety: Report by the Secretariat. 2002:1-6.

[6] Horton R, Das P. Indian health: The path from crisis to progress. Lancet. 2011;377:181-3. [PubMed]

[7] Muralidhar S, Taneja A, Ramesh V. Patient safety culture-perception of health care workers in a tertiary care hospital. Int J Risk Saf Med. 2012;24:191-9. [PubMed]

[8] Guest G, MacQueen KM, Namey EE. Applied thematic analysis. 1st ed. SAGE; 2011.

[9] Galadanci HS. Protecting patient safety in resourcepoor settings. Best Pract Res Clin Obstet Gynaecol. 2013;27:497-508. [PubMed]

[10] Marjadi B, McLaws ML. Hand hygiene in rural Indonesian healthcare workers: barriers beyond sinks, hand rubs and in-service training. J Hosp Infect; 2010;76:256-260. [PubMed]

[11] Sethi AK, Acher CW, Kirenga B, Mead S, Donskey CJ, Katamba A. Infection control knowledge, attitudes, and practices among healthcare workers at Mulago Hospital, Kampala, Uganda. Infect Control Hosp Epidemiol. 2012;33:917-23. [PubMed]

\section{Author Profile}

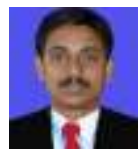

Bobish Kandy is a Retired Indian Navy, Petty Officer Radio and Safety Professional with 22 years of experience currently working as an Officer Fire \& Safety, in Quality \& Risk Section JCIA accredited Hospital (ADNOC-Ruwais Hospital).

Also, a Graduate in Economics from University of Calicut, Post Graduate Diploma in Computer Applications, Diploma in Management from IGNOU New Delhi and qualified in several courses in Safety, Security, CBRNE, Hazmat, ISO, Quality and Environmental standards. He is c urrently perusing MBA in Hospital Management from, Annamalai University.

Project Lead: This study was led by Project Lead Dr. Junior Sundaresh, Associate Professor of Surgery Rajah Muthiah Medical College, Annamalai University, Tamilnadu, India. 